\title{
Prevalence and Associated Factors of Risky Sexual Behaviours Among in-School Youth in Lalibela Town, North Wollo Zone, Amhara Regional Sate, Ethiopia: A Cross-Sectional Study Design
}

\author{
Alebel Yaregal Desale ${ }^{1}$, Mesele Damte Argaw ${ }^{2,}$,, Alemayehu Worku Yalew ${ }^{3}$ \\ ${ }^{1}$ Plan International Ethiopia, Bahir Dar, Ethiopia \\ ${ }^{2}$ Private Health Sector Program, Addis Ababa, Ethiopia \\ ${ }^{3}$ Addis Continental Institute of Public Health, Addis Ababa, Ethiopia
}

Email address:

alebel.yaregal@gmail.com (A. Y. Desale),mdamte5@gmail.com (M. D. Argaw), alemayehuwy@yahoo.com (A. W. Yalew)

To cite this article:

Alebel Yaregal Desale, Mesele Damte Argaw, Alemayehu Worku Yalew. Prevalence and Associated Factors of Risky Sexual Behaviours Among in-School Youth in Lalibela Town, North Wollo Zone, Amhara Regional Sate, Ethiopia: A Cross-Sectional Study Design. Science Journal of Public Health. Vol. 4, No. 1, 2016, pp. 57-64. doi: 10.11648/j.sjph.20160401.18

\begin{abstract}
Adolescence and youth are the periods for great opportunity and hope in human life. They are the periods between childhood and adulthood where by the young people are expected to undergo major physical, emotional, and social developments, with significant impact on their sexual and reproductive health. This study was aimed at assessing the magnitude and factors associated with risky sexual behaviours (RSB) among in-school youth (15-24) in Lalibela Town, Ethiopia. A cross-sectional institution based quantitative survey was conducted in June, 2014. A systematic random sampling technique was used to get the required sample size of 1362 study participants. A structured pretested and self-administered questionnaire was used to collect the data. The univariate statistical analysis was used to describe the variables using tables and graphs. The multivariable logistic regression model was developed and factors associated with risky sexual behaviour were identified. A total of 1332 in-school youth (ISY) with a 97.8\% response rate were included in the study. Five hundred fourteen (38.6\%) in-school youth reported that they have initiated sexual intercourse. The mean age at the first sexual experience with standard deviation (Mean $\pm(\mathrm{SD}))$ was $15.25 \pm(1.85)$ years, Median $=15$ years, Ranges from 11 to 24 years. Among sexually active in-school youth, the prevalence of risky sexual behaviour, students reported at least one of the three risky behaviours which consist of engaging sexual debut before age 18 years, having multiple sexual partners and not consistently using condom was 46.5\% (239/514). The odds of having risky sexual behaviour among urban resident ISY was 1.65 times higher than their counterpart (AOR 1.65; 95\%CI: $1.12-2.43$, Pvalue $<0.001$ ). The odds of risky sexual behaviour among ISY who had peer influence in sexual debut was 2 folds higher (AOR 2.06; 95\%CI: $1.37-3.12$, P-value $<0.001)$ than their counterpart. The odds of the risky sexual behaviour of youth who never chew khat was less by $49 \%$ (AOR 0.51 ; 95\%CI: $0.32-0.80$, P-value $<0.001$ ) than their counterpart or khat chewers. A large proportion of in-school youth engaged in the risky sexual behaviour. Permanent residence, peer pressure, and substance uses are factors associated with risky sexual behaviours among in-school youths. Therefore, improving access to sexual and reproductive health for in-school youth is highly recommended. All concerned partners should work hard to create awareness about the identified factors and consequences of risky sexual behaviours among in school youth in the study area.
\end{abstract}

Keywords: Lalibela, In-School Youth, Substance Use, Risky Sexual Behaviour, Ethiopia

\section{Background}

According to the third national report of Population Census Commission of the Federal Democratic Republic of Ethiopia, one-fifth of its population consists of the age category between 15 to 24 years [1]. Adolescence and youth are the period of great opportunity and hope, whereby young people undergo major physical, emotional, and social development, with significant impact on their sexual and reproductive health [2].

A large proportion of young people in the world are sexually active, which exposes them to the risk of acquiring Sexually 
Transmitted Infections (STIs), including HIV and puts them at risk for unplanned pregnancies [3]. Due to the fact that there are efforts to address the health of young and vulnerable population group aged $15-24$ years. After multiple decades of intervention to mitigate the major adolescent and youth health problem including HIV|AIDS and other sexual transmitted infections risky sexual behaviour remains the major health concern in Ethiopia [4, 5].

The reproductive health needs of young people are believed to be directly affected by socio-economic and cultural contexts $[6-10]$. Youth is the time of initiating sexual experimentation and may include risky behaviour [3]. Many studies documented age of first sexual debut as below 18 years. Young people who initiate sex at an early age face a higher risk of becoming pregnant or contracting STI than young people who delay initiation of sexual activity [11-13]. Some studies documented that youth has knowledge of risky sexual behaviour like having multiple partners and inconsistent condom use. However, they still lack experience in decision making compared to adults [8]. Engaging in sexual debut in exchange for money or as a gift with much older partners increases the risk of acquiring STIs [14]. In addition, there is evidence that a linear increase of substances uses like khat, alcohol and cigarette with a higher prevalence of having risky sexual behaviours $[15,16]$. Therefore, these substances are at the top of the list among the predictors of risky sexual behaviours.

The subjects of this study were in-school youth $(15-24$ years old) who were attending their high schools, preparatory schools, and technical and vocational education training (TVET) centres. Students in the stated levels are considered knowledgeable about the mode of transmission and prevention of HIV|AIDS and other STIs. So they are expected to protect themselves better and have a safer sexual behaviour than their counterparts, who were out-of-school youths [3]. In addition, the national adolescent youth reproductive health strategy $(2006-2015)$ endorses the health need this special group can be addressed through accelerated, flexible and participatory activities from all committed partners [4]. However, the effect of the intervention was not evaluated in the study area.

Therefore, the aim of this study was, to assess the magnitude of risky sexual behaviours and associated factors that predispose in-school youths in Lalibela town. As the town is a tourist attraction place that brings people around the globe together the probability of being exposed for risky sexual behaviours related health problems especially among young population segment is unquestionable. Therefore, the findings of this study were believed to play significant role in the process of designing proper health information system for action and initiate youth friendly services to address the risky sexual behaviours by different sectors and actors.

\section{Operational Definition}

Youth: According to the United Nations youth is defined as persons between 15-24 years of age [3]. The Ethiopian
National Youth Policy defines youth as persons aged from 15 to 29 years [17]. For this study, since most of secondary school students fall in the age category $15-24$ years, we adopted the United Nations' recommended age category.

Risky Sexual Behaviours (RSBS): is defined as the practice of at least one of the three outcome variables: initiating sexual debut before the age of 18 , inconsistent condom use and/or having multiple sexual partners.

Substance use: refers to the use of substances such as alcohol, khat leaves (Catha edulis) and tobacco.

\section{Methods}

\subsection{Study Settings and Design}

A cross-sectional institution based quantitative study was conducted in Lalibela town of North Wollo Administrative Zone, at Amhara Region in Ethiopia. Lalibela is located at $12^{\circ} 01 ' 54^{\prime \prime} \mathrm{N}$; and $39^{\circ} 02^{\prime} 28^{\prime \prime} \mathrm{E}$ with an altitude of 2480 meters above sea level. The town is located $700 \mathrm{~km}$ and 300 km away from Addis Ababa and Bahir Dar, respectively. The town also serves as the centre of the neighbouring districts for different social, economic and cultural services, including the preparatory school and Technical and Vocational Education and Training (TVET) centre [29].

In terms of infrastructure development, there is one hospital, one health centre, three primary schools, one high school, one preparatory school and one TVET. In the academic year 2013/14, there were 3502 students (i.e. 1553 $(44.3 \%)$ males and 1949 (55.6\%) females) enrolled in the above three levels of education. Of these, 2253(64.3\%) were in high school, $759(21.6 \%)$ were in preparatory and 490 (13.9\%) were in TVET in the year 2013/14[18].

\subsection{Sample Size}

The sample size of this study was determined using single population proportion formula [19]. Stat Cal interface of Epi info Software, version 3.5.2 (CDC, Atlanta, GA, USA) was used to calculate the sample size. The assumption used in calculating the sample size was a proportion of $34.1 \%$ of inschool youth who ever had risky sexual behaviour (i.e. sex without a condom), was documented in study Behavioural Survey Surveillance (BSS) II [20]. D $=4 \%$ states the marginal error and $\mathrm{CI}=95 \%$ is the confidence interval of certainty $(\alpha=0.05)$. Based on this assumption the actual sample size for the study computed was determined, using single population proportion formula as indicated below. In addition, a non-response rate of $10 \%$ was added. Accordingly the calculated sample was 592. But, through reviewing literature we found the proportion of students who were sexually active is $42.9 \%$ [21]. Hence, to increase the precision of the point estimates and power of the study the investigators decided to use a correction factor 2.3 (1/0.429). Therefore, the total estimated sample size was 1,362 .

\subsection{Sampling}

First students were stratified based on their level of 
schooling. Then, a systematic random sampling technique was applied to select individuals in each year of study from the roster in their respective grades and levels. Students (males and females) from each level of schooling were selected proportionally to their population size. Then, after calculating the sampling interval and choosing the $1^{\text {st }}$ number randomly every third student was selected.

\subsection{Data Collection Tools and Procedures}

We adopted the data collection tool developed by Cleland, Ingham and Stone that is recommended by WHO in sexual and reproductive health studies [22]. The structured questionnaire was originally developed in English, then translated into the local language, Amharic, and translated back to English to ensure consistency of the tool. The tool was pretested among fifty grade ten students in Bahir Dar City. At the end of pretesting, a discussion with participants was arranged and facilitated by the principal investigator. Notes were taken on any language barriers and difficulties that were found in the questionnaire. Based on the findings changes were made on the instruments accordingly. The responses of in school youth were scored and the internal consistence of the tool was determined using Cronbach's Alpha. The scoring process consists of engage in sexual debut ' 1 ' otherwise ' 0 '; age of first sexual debut ' 1 ' for $<18$ years old, otherwise ' 0 ' for no sexual debut and age greater or equal to 18 years; Multiple sexual partner ' 1 ' for having two or more sexual partners in life otherwise ' 0 ' for no sexual debut or having faithful sexual relationship with single partner; and inconsistent condom use score ' 1 ' otherwise no sexual debut and consistent condom use ' 0 '. The result shows that the Cronbach's alpha ranges from 0.632 to 0.854 which show the scale is reliable (Table 1).

Table 1. Reliability test result of the survey tool, June 2014.

\begin{tabular}{|c|c|c|c|c|}
\hline Ser No & Variables & Respondents & Mean $\pm($ SD $)$ & Alpha Reliability \\
\hline 1 & Engage in Sexual debut & 50 & $0.32 \pm(0.47)$ & 0.632 \\
\hline 2 & Age of first sexual debut & 50 & $0.24 \pm(0.43)$ & 0.683 \\
\hline 3 & Multiple Sexual partner & 50 & $0.12 \pm(0.32)$ & 0.854 \\
\hline 4 & Inconsistent Condom Use & 50 & $0.16 \pm(0.37)$ & 0.833 \\
\hline
\end{tabular}

Before the questionnaire was self-administered, the students were provided with an orientation in their respective classrooms about issues related to the purpose of the study, the selection criteria and confidentiality. To complete the task of data collection, ten data collectors ( 5 males and 5 females) who achieved a Bachelor degree were recruited and attended a two days long training on basic principles of behavioural research techniques, objective of the research, content of each question and response, and ethical issues. One of the researchers ensures the quality of the whole data collection process through supervision. The selected students responded to the questionnaire in separate rooms. The data were collected in June 2014.

\subsection{Measurements}

The dependent variable was risky sexual behaviour; in the regression analysis it was coded ' 1 ' while ' 0 ' was coded for safe sexual behaviour. The independent variables were age, sex, educational status, permanent residence, pocket money (income), living arrangements, peer pressure, khat chewing and drinking alcohol.

\subsection{Data Analysis}

The data were double entered into Microsoft Access 2010 office facility (Microsoft Corporation, Redmond, WA) and cleaned by the investigator for improved accuracy. The cleaned data were exported and analysed using Statistical Packages for Social Sciences research (SPSS IBM version 20) [23]. The magnitude of risky sexual behaviour was determined using descriptive statistics frequencies and percentages.

Univariate logistic regression analysis was made by considering the dependent variable risky sexual behaviour and several independent variables. Crude Odds Ratios (CORs) with 95\% confidence intervals were estimated to assess the association between each independent variable and risky sexual behaviour together with the $p$-value. Independent $t$ test was employed to identify difference in age of sexual debut by sex. A multivariate logistical regression model was developed after identifying candidate variables with Wald statistic $\mathrm{P}<0.25$ [24]. Adjusted Odds Ratios (AORs) with $95 \%$ confidence intervals were estimated to determine the strength of association, and a p-value $<0.05$ was set to declare statistical significance in multivariable analysis.

\subsection{Ethical Considerations}

Ethical clearance was obtained from Institutional Review Board (IRB) of University of Gondar and Addis Continental Institute of Public Health. Permission to conduct the data collection was obtained from Amhara Regional State Education Bureau and an official letter of support was written to the respective schools. In addition, the recommendation of Ethiopian Federal Ministry of Health (EFMOH) minimum of age of consent i.e.15 years and above are considers [25]. Written informed consent was obtained from each participant. Participants were informed that they have full right to discontinue or refuse participation in the study. In order to protect confidentiality, personal identifiers were not included on the written questionnaires. The investigators were responsible for keeping and protecting the confidentiality of the information provided by all the respondents. After receiving their consent, the data were collected by self-administering the questionnaire. 


\section{Results}

A total of 1,362 in-school youth participated in the study, of which 1332 properly completed, making the response rate 97.8 per cent. A little higher than half $(55.3 \%)$ of the participants were females. The mean age and standard deviation of the study participants were $17.39 \pm 1.63$ years. The majority $(96.1 \%)$ of the respondents were Orthodox Christians followed by (2.2\%) Muslim. Almost half of the respondents' 727 (54.6\%) live in urban areas (Table 2).

Table 2. Socio demographic characteristics of study participants (in-school youth) $n=1,332$, Lalibela town, June 2014.

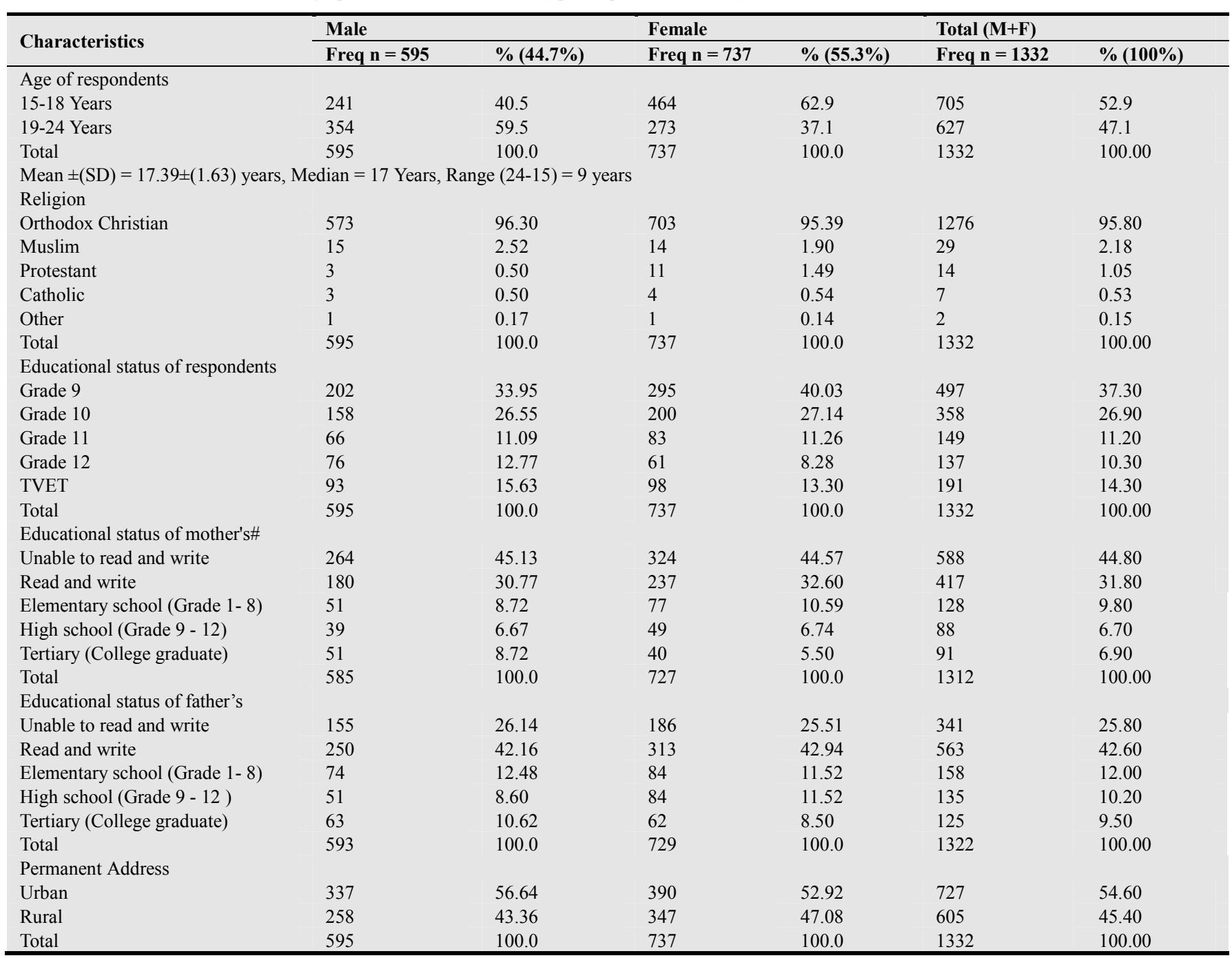

$\mathrm{NB}: \# \mathrm{n}=1312$

\subsection{Sexual Experiences}

A little higher than one-third of in-school youth $(38.6 \%)$ were sexually active. The mean age at first sexual debut with standard deviation was $15.25 \pm 1.84$ years. In addition, the magnitude of early sexual debut was 39.5\% (203/514). Moreover, among the sexually active female students, a little less than half $(41.2 \%)$ have risky sexual behaviour. Similarly, close to half of the male counterparts $(52.2 \%)$ also have at least one risky sexual encounter. On average, female inschool youth in Lalibela town began having sexual intercourse earlier (mean $=15.01 \pm 1.54$ with standard error 0.094 ) than their male counterpart (Mean $=15.51 \pm 2.10$ with standard error 0.131). This difference was statistically significant at $(\mathrm{t}(512)=3.10, \mathrm{P}=0.002)$.

\subsection{Reasons for Sexual Debut and Magnitude of Risky Sexual Behaviour}

The main reasons reported for the first sexual debut were related to personal desire $328(63.8 \%)$, followed by peer pressure $165(32.1 \%)$, influence of substance use $53(10.3 \%)$, coercion $54(10.5 \%)$, to earn money $43(8.4 \%)$, and partners' interest $137(26.7 \%)$. Close to half of the ISY 235(45.7\%) had their first sexual experience with their girl/boyfriends, $119(23.2 \%)$ with a casual partner, $124(24.1 \%)$ with their spouse, 30(5.8\%) with a tourist and the rest $6(1.2 \%)$ suggested others. In terms of the lifetime (total) number of sexual partners among in-school youth in Lalibela town, 292(56.8\%) reported one sexual partner, 101 $(19.6 \%)$ reported two sexual partners, $121(23.5 \%)$ reported three or more sexual partners. Similar, the prevalence of inconsistent 
Condom use were reported by $236(45.9 \%)$ sexually active ISY. The most cited reason for not consistently using a condom were the shame of buying condoms $35.6 \%$ (84/236), followed by trusting a partner $29.6 \%$ (70/236), a partner's refusal $25.0 \%(59 / 236)$ and not available 9.8\% (23/236). Among sexually active in-school youth, the prevalence of risky sexual behaviour, students reported at least one of the three risky behaviours which consist of engaging sexual debut before age 18 years old, having multiple sexual partners and not consistently using condom was 46.5\% (239/514).

\subsection{Substance Use Behaviour}

The study revealed that among the respondents, 190 $(14.3 \%)$ of them used to chew khat. In connection with the chewing patterns, $153(80.5 \%)$ of the respondents chewed 23 times a month, $31(16.3 \%)$ of them chewed 2-3 times a week and $6(3.1 \%)$ chewed on a daily basis.

Almost half 651 (48.8\%) of the in-school youth reported that they used to drink alcohol. Among these, 496 (76.2\%) drank 2-3 times per month, $124(19.0 \%)$ drank 2-3 times a week and the remaining $31(4.7 \%)$ drank every day. The most commonly cited reasons for drinking alcohol were to get personal pleasure $(57.8 \%)$ followed by peer pressure $(35.5 \%)$, and the third reported reason were socialization (32.9\%). Sixty $(4.5 \%)$ of the respondents used to smoke cigarettes, among these $30(50.0 \%), 16(26.6 \%)$ and $14(23.3 \%)$ of the respondents respectively used to smoke 2-3 times in a month, 2-3 times in a week and on daily basis respectively.

Table 3. Uni-variate and multivariate analysis of socio-demographic and economic variables against Risky Sexual Behaviour among in-school youth in Lalibela Town, June 2014

\begin{tabular}{|c|c|c|c|c|}
\hline \multirow{2}{*}{ Characteristics } & \multicolumn{2}{|c|}{ Risky Sexual Behaviour } & \multirow{2}{*}{ COR $(95 \%$ CI $)$} & \multirow{2}{*}{ AOR (95\%CI) } \\
\hline & Yes N(\%) & No N(\%) & & \\
\hline \multicolumn{5}{|l|}{ Sex of respondent } \\
\hline Male & $129(52.2 \%)$ & $118(47.8 \%)$ & $1.56(1.10,1.27)^{*}$ & $1.30(0.85,1.97)$ \\
\hline Female & $110(41.2 \%)$ & $157(58.8 \%)$ & 1 & 1 \\
\hline \multicolumn{5}{|l|}{ Age in category } \\
\hline $15-18$ Years & $194(45.5 \%)$ & $232(54.5 \%)$ & $0.89(0.62,1.27)$ & $0.93(0.58,1.50)$ \\
\hline $19-24$ Years & $45(51.1 \%)$ & $43(48.9 \%)$ & 1 & 1 \\
\hline Grade 9 & $100(47.4 \%)$ & $111(52.6 \%)$ & $0.78(0.46,1.33)$ & $0.89(0.47,1.72)$ \\
\hline Grade 10 & $47(40.2 \%)$ & $70(59.8 \%)$ & $0.58(0.32,1.05)$ & $0.65(0.34,1.26)$ \\
\hline Grade 11 & $18(38.3 \%)$ & $29(61.7 \%)$ & $0.54(0.25,1.14)$ & $0.53(0.24,1.19)$ \\
\hline Grade 12 & $35(53.0 \%)$ & $31(47.0 \%)$ & $0.98(0.50,1.92)$ & $1.09(0.53,2.26)$ \\
\hline TVET & $39(53.4 \%)$ & $34(46.6 \%)$ & 1 & 1 \\
\hline \multicolumn{5}{|l|}{ Permanent Residence } \\
\hline Urban & $138(54.2 \%)$ & $115(45.8 \%)$ & $1.84(1.29,2.61)^{*}$ & $1.65(1.12,2.43)^{*}$ \\
\hline Rural & $103(39.2 \%)$ & $160(60.8 \%)$ & 1 & 1 \\
\hline Regular (Daily) & $61(39.4 \%)$ & $95(60.6 \%)$ & $0.65(0.440 .95)^{*}$ & $0.85(0.55,1.30)$ \\
\hline Irregular & $178(49.7 \%)$ & $180(50.3 \%)$ & 1 & 1 \\
\hline \multicolumn{5}{|l|}{ Living arrangement } \\
\hline Single Parent, Peer & $115(44.7 \%)$ & $142(55.3 \%)$ & $0.87(0.61,1.23)$ & \\
\hline With Both Parents & $124(48.2 \%)$ & $133(51.8 \%)$ & 1 & \\
\hline \multicolumn{5}{|l|}{ Pocket money } \\
\hline Yes & $148(47.3 \%)$ & $165(52.7 \%)$ & $1.08(0.76,1.54)$ & \\
\hline No & $91(45.3 \%)$ & $110(54.7 \%)$ & 1 & \\
\hline \multicolumn{5}{|l|}{ Peer influence } \\
\hline Yes & $97(40.6 \%)$ & $142(59.4 \%)$ & $2.07(1.42,3.03)^{*}$ & $2.06(1.37,3.12)^{*}$ \\
\hline No & $68(24.7 \%)$ & $207(75.3 \%)$ & 1 & 1 \\
\hline \multicolumn{5}{|c|}{ Open Discussion with family } \\
\hline Yes & $119(49.8 \%)$ & $120(50.2 \%)$ & $0.66(0.46,0.93)^{*}$ & $0.68(0.46,1.01)$ \\
\hline No & $165(60.0 \%)$ & $110(40.0 \%)$ & 1 & 1 \\
\hline \multicolumn{5}{|l|}{ Chew khat } \\
\hline \multicolumn{5}{|l|}{ Drunk Alcohol } \\
\hline Never drink alcohol & $77(39.3 \%)$ & $119(60.7 \%)$ & $0.62(0.43,0.89)^{*}$ & $0.79(0.53,1.19)$ \\
\hline Used to drink alcohol & $162(50.9 \%)$ & $156(49.1 \%)$ & 1 & 1 \\
\hline \multicolumn{5}{|c|}{ Where do you spend your spare time } \\
\hline Library & $55(35.3 \%)$ & $101(64.7 \%)$ & $1.49(0.45,4.92)$ & $2.03(0.57,7.12)$ \\
\hline Home & $93(48.9 \%)$ & $97(51.1 \%)$ & $2.64(0.81,8.57)$ & $3.86(1.12,13.37)^{*}$ \\
\hline Alcohol house & $21(65.6 \%)$ & $11(34.4 \%)$ & $5.25(1.35,20.39)^{*}$ & $5.00(1.20,20.73)^{*}$ \\
\hline Khat house & $21(77.8 \%)$ & $6(22.2 \%)$ & $9.62(2.21,41.46)^{*}$ & $5.84(1.25,27.24)^{*}$ \\
\hline Youth Centre & $26(60.5 \%)$ & $17(39.5 \%)$ & $4.20(1.14,15.39)^{*}$ & $4.66(1.20,18.04)$ \\
\hline Church & $19(37.3 \%)$ & $32(62.1 \%)$ & $1.63(0.45,5.85)$ & $2.31(0.59,8.94)$ \\
\hline Other (Support family) & $4(26.7 \%)$ & $11(73.3 \%)$ & 1 & 1 \\
\hline
\end{tabular}

NB: In multi-variable logistic regression we consider $\mathrm{P}<0.25$ form uni-variate analysis. *: $\mathrm{P}$ value $<0.05$ 


\subsection{Factors Associated with Risky Sexual Behaviour}

The univariate logistic regression analysis was conducted to identify any statistically significant relationship between the dependent variable (risky sexual behaviour) and independent variables (Table 3). The odds of risky sexual behaviour $(\mathrm{P}<0.05)$ for male in-school youth was 1.56 times higher (COR 1.56; 95\% CI: $1.10-1.27$, P- value $<0.001$ ) than their counterpart. The Urban in-school youth had risky sexual behaviour 1.84 folds higher (COR 1.84; 95\%CI: 1.84 $-2.6, \mathrm{P}$-value $<0.001)$ than youth from rural areas. The odds of risky sexual behaviour among youth whose sexual debut was influenced by their peers was 2.07 times higher (COR 2.07; 95\%CI: 1.42 - 3.03, $\mathrm{P}$-value $<0.001)$ than their counterpart.

In-school youth who reported regular attendance of religious services had 0.65 times lower risk of risky sexual behaviour than the ISY irregular visitors (P-value $=0.05$ ). The risky sexual behaviour among ISY who never chewed khat and never drank alcohol was 0.62 and 0.49 times lower than their counterparts, respectively.

We developed a model to control all confounder variables and identified the factors influencing risky sexual behaviour among the sexually active in-school youth in the study area. The odds of having risky sexual behaviour among urban resident ISY were 1.65 times higher than their counterpart (AOR 1.65; 95\%CI: $1.12-2.43$, P-value $<0.001$ ). The odds of RSB among ISY who had peer influence in the sexual debut were 2-folds higher (AOR 2.06; 95\%CI: 1.37 - 3.12, P-value $<0.001)$ than their counterpart. The odds of the risky sexual behaviour of youth who never chewed khat were 0.51 times lower (AOR 0.51; 95\%CI: $0.32-0.80$, P-value $<0.001$ ) than their counterpart, khat chewers. The odds of youth who spent their spare time in alcohol houses and khat houses were 5.0 and 5.8 times higher than ISY who spent their time in supporting their family.

\section{Discussions}

In this study, slightly higher than one-third of the respondents 514 (38.6\%) among in-school youth had started sexual intercourse. This finding was in line with $33.3 \%$ to $42.9 \%$ in a recent study conducted in Jimma zone, West Ethiopia and Bahir Dar Town in-school students [15, 21, 26, 27]. This was much higher than the $25.0 \%$ prevalence documented in Ghana [7]. A study conducted among high school students in Kenya also documented more than half of the youth engaged in pre-marital sexual intercourse [8]. These variations could be due to the time and cultural differences.

The mean age at sexual debut (intercourse) was 15.25 years with differences in gender, where females (15.01 years) started earlier than males (15.51 years). This is statistically significant according to the independent t-test with $\mathrm{t}(512)=$ 3.10, $\mathrm{P}=0.002$. Fantanhu and Mamo [15] reported the odds of female in-school youth to initiate sexual debut earlier than their counterpart was 1.6 times higher. This finding was a little higher than the findings in Kenya's Bondo District where 13 years was the mean age [8] and 14.8 years in Ghanaian youth [7]. Nevertheless, it was in alignment with a study conducted in northeast Ethiopia, which documented that females tend to engage in sexual intercourse earlier than males [11]. However, a study conducted among youth in secondary school in Kenya's Bondo district had shown that males initiate sexual intercourse a year earlier than females at the mean age of 13 and 14 years old, respectively [8].

In this study, the majority of in-school youth had their first sexual intercourse with their boy/girlfriend 235 (45.7\%). A study conducted in West Amhara by Bogale and Seme [13] reported $40.8 \%$ of in-school youth had their first sexual encounter with an in school boy/girlfriend. The second most common reported partner in this study was a casual partner for $23.2 \%$ of the subjects, and $30(5.8 \%)$ of them reported that they had sex with a foreign tourist. This is consistent with the Kenyan youth whereby $4.0 \%$ of them had sexual intercourse with strangers [8]. With regard to the perception that having sex with foreign tourists exposes them to STIs, a significant proportion of them $(53.8 \%)$ did not believe they were more at risk. However, in an in-depth interview study on sexual health and HIV in travellers and expatriates suggested that there is a well-established association between travellers and the acquisition of STIs [26].

The magnitude of risky sexual behaviours was also determined. At least one out of two sexually active in-school youth 239 (46.5\%) had risky sexual behaviours. This finding was consistent with a study conducted in Gondar town among preparatory students $43.3 \%$ had risky sexual behaviours [29]. A little higher than the finding of the study conducted in Jimma zone where there was 30.8\% among preparatory students who reported their history of having multiple sexual partners [28] and $31.0 \%$ of the Ghanaian youth reported a similar history of having multiple sexual partners [21].

Among in-school youth, those whose permanent residences were documented as rural areas were less likely to be engaged in risky sexual behaviour than their counterpart in urban residents. This finding was in line with a study conducted in eight African countries [6].

The prevalence of substance use among in-school youth varies depending on the substances being used. Alcohol and khat were the two substances used by a larger proportion of in-school youth in the study area. We found that $14.3 \%$ of inschool youth had ever chewed khat. Derese, Seme and Misganaw [26] documented in their survey a prevalence of $20.3 \%$ of youth were khat chewers. Unlike chewing khat, almost half of the study participants in Lalibela town (48.8\%) drank alcohol. This finding was much higher than the reported prevalence of $37 \%$ of in-school youth consuming alcohol in Jimma zone and the $17.5 \%$ of the Haromaya university students $[21,26,30]$.

The lifetime number of sexual partners reported among inschool youth in Lalibela town; 292 (56.8\%) had one, 101 
(19.6\%) had two, $121(23.5 \%)$ had three or more partners. This finding was closely related with the findings among Ghanaian youth who reported one sexual partner $66.3 \%(\mathrm{~m}=$ $61.5 \% \mathrm{f}=70.5 \%)$, two $14.9 \%(\mathrm{~m}=13.8 \% \mathrm{f}=16.5 \%)$ and three or more $18.2 \%(\mathrm{~m}=12.35 \% \mathrm{f}=6.2 \%)$ [7]. Moreover, in the study area almost half of sexually active ISY inconsistently uses condom. This finding was a little previously reported $34.0 \%$ of ISY inconsistently uses condom in BSS II [20].

\section{Conclusions}

The study found a significant proportion of risky sexual behaviour among in-school youth in Lalibela town. A little higher than one-third of the study subjects had engaged in a sexual debut, from which close to half of them involved in the risky sexual behaviour.

Improving access to sexual and reproductive health programs for in-school youth is highly recommended. All concerned bodies should work together to create awareness on sexual and reproductive needs and services. Dissemination of tailored health messages for in-school youth through friendly reproductive health services is recommended.

Limitation: Lalibela District is selected using purposive sampling methods so the findings couldn't be generalized to other places. Since the data collected request sexual and related risky behaviour, there is a high possibility of underreporting (it is not free from social desirability bias). It is highly likely that this study contains a recall bias, especially, in estimating age at first sexual experiences.

\section{List of Abbreviation}

$\begin{array}{ll}\text { AIDS } & \text { Acquired Immune Deficiency Syndrome } \\ \text { AOR } & \text { Adjusted Odds Ratio } \\ \text { BSS } & \text { Behavioral Survey Surveillance } \\ \text { CDC } & \text { Centers for of Disease Control and Prevention } \\ \text { CI } & \text { Confidence Interval } \\ \text { COR } & \text { Cruds Odds Ratio } \\ \text { EFMOH } & \text { Ethiopian Federal Ministry of Health } \\ \text { HIV } & \text { Human Immune-Deficiency Virus } \\ \text { IRB } & \text { Institutional Review Board } \\ \text { ISY } & \text { In-School Youth } \\ \text { RSB } & \text { Risky Sexual Behaviors } \\ \text { SD } & \text { Standard Deviation } \\ \text { SPSS } & \text { Statistical Package for Social Science } \\ \text { STIs } & \text { Sexually Transmitted Infections } \\ \text { TVET } & \text { Technical, Vocational, Education and Training } \\ \text { UNAIDS } & \text { Joint United Nation Program on HIV/AIDS } \\ \text { UNICEF } & \text { United Nations Children's Fund } \\ \text { USAID } & \text { United States Agency For International } \\ \text { WHO } & \text { Development World Health Organization }\end{array}$

\section{Acknowledgements}

The authors would like to express their gratitude to Gondar University and Addis Continental Institute of Public Health for approving this research. We are thankful for Plan International Ethiopia for funding; Metasebia Asfaw and Cheru Abebe for their moral and financial support; Marie Bridonneau and Sofia Murad for their editorial feedbacks.

We are indebted to all data collectors and supervisor's for their dedication and effort invested during the data collection process. We are obliged to thank all in school youth who shared us their opinion and spend their invaluable time through completing the questionnaire.

\section{References}

[1] Ethiopian Federal Population Census Commission (EFPCC): Summary and statistical report of the 2007 population and housing Census: population size by age and sex. Addis Ababa: EFPCC; 2008.

[2] ICF International: Atlas of Youth Reproductive Health: Data from the 2011 Ethiopia Demographic and Health Survey. Calverton, Maryland, USA: ICF International; 2012.

[3] United State Agency for International Development (USAID): Youth in development policy: Realizing the demographic opportunity. Washington, DC: USAID; 2012.

[4] Ethiopian Federal Ministry of Health (EFMOH): National Reproductive Health Strategy 2006 - 2015. Addis Ababa: EFMOH; 2006.

[5] Joint United Nation Program on HIV|AIDS (UNAIDS): Global Report: UNAIDS report on the Global AIDS epidemic 2013. Geneva: UNAIDS; 2013.

[6] Peltzer K: Early sexual debut and associated factors among inschool adolescents in eight African Countries. Acta Pædiatrica 2010; 99(8): 1242-1247. DOI: $10.1111 / \mathrm{j} .1651$ 2227.2010.01874.x.

[7] David, D. Substance use and risky sexual behaviours among sexually experienced Ghanaian youth. BMC Public Health. 2012; 12: 571 .

[8] Lylian A, Paul O, and Lucas O: Sexual risk-taking behaviours among youth in secondary schools in Bondo district, Kenya. Greener Journal of Educational Research 2013; 3(1):001-006.

[9] Tilahun M, Mengistie B, Egata G, and Reda AA: Health Workers attitudes towards sexual and reproductive health services for unmarried adolescents in Ethiopia. Reproductive Health 2012; 9(19): 1-7.

[10] Adirew YM, Worku AG, and Mengesha, ZB: Knowledge of reproductive and sexual right among university Students in Ethiopia: Institutional - based Cross- Sectional. BMC International Health and Human Right 2013; 13(12).

[11] Central Statistical Agency [Ethiopia] and ICF International. Ethiopia Demographic and Health Survey 2011. Addis Ababa, Ethiopia and Calverton, Maryland, USA: Central Statistical Agency and ICF International; 2012.

[12] Mazengia F, and Worku A: Age of sexual initiation and a factor associated with it among youths in North East Ethiopia. Ethiopia Journal of Health Development 2009; 23(2): 154-162. 
[13] Bogale A, and Seme A: Premarital sexual practices and its predictors among the in-school youth of Shendi town, West Gojjam Zone, North Western Ethiopia. Reproductive Health 2014; 11(49).

[14] Mengistu TS, Melku AT, Bedada BD, and Eticha BT: Risks for STIs/HIV infection among Medawalabu University Students, South East, Ethiopia: a Cross-Sectional Study. Reproductive Health 2013; 10(38).

[15] Fantahun N, and Mamo A: Risky sexual behaviour and associated factors among male and female students in Jima Zone preparatory schools, South West Ethiopia: Comparative Study. Ethiop J Health Sci 2014; 24(1): 59-68.

[16] Dadi, AF, and Teklu FG: Risky sexual behaviour and associated factors among grade 9- 12 students in Humera secondary School, Western Zone of Tigray, NW Ethiopia 2014. Science Journal of Public Health 2014; 2(5): 410-416.

[17] Ethiopian Federal Ministry of Youth Sport and Culture (EFMOYSC): National youth policy. Addis Ababa: Federal Ministry of Youth Sport and Culture; 2004.

[18] Lalibela Town Culture, Tourism and Park Development Office (LTCTPDO). Semiannual performance report of the Ethiopian sustainable tourism development project (ESTDP). Lalibela: LTCTPDO; 2014.

[19] Daniel WW: Biostatistics: a foundation for analysis in the health sciences. 4th edition. John Wiley \& Sons Inc. 1987; $155-156$.

[20] Mitike G, Meknonnen T, Ayele R, Gadisa T, Enqusillasie F, Lemma W \& Woldu A: HIV|AIDS Behavioral Surveillance Survey (BSS). Round Two. Federal Ministry of Health, Addis Ababa: Ethiopia, 2005.

[21] Abebe M, Tsion A, Netsanet F: Living with parents and risky sexual behaviours among preparatory school students in Jimma zone, Southwest Ethiopia. African Health Sciences 2013; 13(2): 498-506.
[22] Cleland J, Ingham R, Stone N: Special Programme of Research, Development and Research Training in Human Reproduction. UNDP/UNFPA/WHO/World Bank; 2001.

[23] SPSS. IBM SPSS Statistics Base 20. SPSS Inc., Chicago; 2011.

[24] Hosmer D W, \& Lemeshow S (Eds.): Applied Logistic Regression. New York: Wiley. 2000.

[25] Federal Ministry of Health: Guideline for HIV counselling and testing in Ethiopia. Addis Ababa, FMOH: 2007.

[26] Croughs M, Remmen R, and Van den Ende J: The effect of Pre-Travel Advice on sexual risk behaviour on abroad: a systematic review. Journal of Travel Medicine 2014; 21(1): 45-51.

[27] Mulugeta, $\mathrm{Y}$ and Berhane Y: Factors associated with premarital sexual debut among unmarried high school female students, Bahir Dar Town, Ethiopia: Cross Sectional study. Reproductive Health 2014; 11(40): 1-6.

[28] Negeri EL: Assessment of risky sexual behaviour and risk perception among youth in western Ethiopia: the influence of family and peers: a comparative cross-sectional study. BMC Public Health 2014; 14(301): 1-12.

[29] Shiferaw Y, Alemu A, Girma A, Getahun A, Kassa A, Gashaw A, Alemu A, Teklu T, and Gelaw B: Assessment of knowledge, attitude and risk behaviours towards HIV|AIDS and other sexual transmitted infection among preparatory students of Gondar town, North West Ethiopia. BMC Research Note 2011; 4: 505.

[30] Derese, A, Seme, A, and Misganaw C: Assessment of risky sexual behaviour among Haromaya University Students, Ethiopia. Science Journal of Public Health 2014; 2(2): 102110. Doi: $10.11648 /$ j.sjph.20140202.19. 